\title{
Vulnerable yet relevant: the two dimensions of climate-related financial disclosure
}

\author{
Irene Monasterolo ${ }^{1,3}(\mathrm{D}) \cdot$ Stefano Battiston ${ }^{2} \cdot$ \\ Anthony C. Janetos ${ }^{3} \cdot$ Zoey Zheng $^{3}$
}

Received: 3 May 2016 / Accepted: 13 October 2017 / Published online: 27 November 2017

(C) The Author(s) 2017. This article is an open access publication

\begin{abstract}
Market-based solutions to climate change are widely advocated by financial actors and policy makers in order to foster a smooth transition to a low-carbon economy. A first important limiting factor to this approach is widely recognized to be the imperfect information on investors' portfolios' exposure to climate-related risks. While better disclosure of climaterelevant information is often recommended as a remedy, the current lack of concise and comparable measures of portfolios' exposure to climate risk fails to provide major investors with the full incentives to reallocate their portfolios. A second limiting factor arises from the fact that in the context of the low-carbon transition, it is not clear how to measure the market share of participants because many economic sectors produce greenhouse gases (GHG) emissions or induce them along the supply chain. The lack of common and concise measures of the relevant market share hampers the ability of policy makers to ensure fair competition policies and the ability of major investors to assess the effects of their own and their competitors' portfolio reallocation. To address these two gaps, we propose two novel and complementary indices: (i) the "GHG exposure," capturing the exposure of single investors' portfolios to climate transition risks, and (ii) "GHG holding," capturing the market share of each financial actor weighted by its contribution to GHG emissions. We illustrate the use of the indices on a dataset of portfolios of equity holdings and loans in the Euro-Area, and we discuss the policy implications for the low-carbon transition.
\end{abstract}

Electronic supplementary material The online version of this article (https://doi.org/10.1007/s10584-0172095-9) contains supplementary material, which is available to authorized users.

Irene Monasterolo

irene.monasterolo@wu.ac.at

1 Vienna University of Economics and Business, Welthandelsplatz 1, D5, 1020 Vienna, Austria

2 FINEXUS - Center for Financial Networks and Sustainability, Department of Banking and Finance, University of Zurich, 8032 Zurich, Switzerland

3 Frederick S. Pardee Center for the Study of the Longer Range Future, Boston University, 67 Bay State Road, Boston, MA 02215, USA 


\section{Introduction}

Both business and financial actors, and policy makers have been increasingly advocating for market-based solutions to climate change. While the imperfect information on investors' portfolios' exposure to climate-related risks is usually recognized as an important limiting factor to a market-based approach (Mas-Colell et al. 1995; Greenwald and Stiglitz 1986), better disclosure of climate-relevant information is recommended as a remedy: "given the right information, investors are expected to deliver the best climate solutions" (Carney and Bloomberg 2016). At this regard, the G20's Task Force for Climate-Related Financial Disclosures (TCFD), created by the Financial Stability Board (FSB), highlighted the need for more transparency regarding companies and financial actors' exposure to investments contributing to greenhouse gas (GHG) emissions, and the need for tools to assess risks and opportunities related to climate change (FSB TCFD 2017).

On the one hand, climate risk could materialize as a consequence of damages to physical assets, natural capital, and/or human lives as a result of climate-induced extreme weather events (IPCC 2014). In case of failure to meet the $2^{\circ} \mathrm{C}$ target, climate risks could materialize for many investors as well as affect negatively GDP, governments' budgets, and, indirectly, sovereign bond values. The entity of the global climate "Value-at-Risk" due to climateinduced physical damages has been estimated by Dietz et al. (2016) in approximately 24.2 trillion (trn) USD of lost financial assets. However, at the level of individual assets and portfolios, the lack of information on climate risk prevents investors from proper risk pricing.

On the other hand, climate risks could also result from the transition to a low-carbon economy (i.e., transition risk, ESRB 2016; Batten et al. 2016). In this context, there are at least three sources of shocks that could limit the ability of market participants to fully anticipate price adjustments of carbon-intense assets. The first source is technological shocks - e.g., a fast decrease in renewable energy production costs can create or destroy value in the fossil fuels and in the renewable energy sectors, respectively (Unruh 2000; Foxon 2006). The second source is scientific discovery shocks - e.g., the new evidence on methane emissions from permafrost thaw, suggesting a possible acceleration of $\mathrm{CO}_{2}$ concentration growth (Anthony et al. 2016); or the new evidence that current climate measures to limit global warming agreed at COP21 would still fail to reach the $2^{\circ} \mathrm{C}$ target (Rogelj et al. 2016). The third source is climate policy shocks - e.g., the success in reaching an agreement at COP21 came as a surprise to many observers, while the 2017 position of the US administration towards climate change would have not been correctly predicted by most observers in 2016. Many recent studies suggest that government, business, and financial sectors should care about the potentially destabilizing role of climate policies aimed at reaching the $2{ }^{\circ} \mathrm{C}$ target through the so-called carbon stranded assets (Caldecott and McDaniels 2014; Leaton 2012). The climate Value-atRisk due to climate policy shocks could be relevant for individual pension funds and investment funds through their holdings in climate- policy-relevant sectors (Battiston et al. 2017).

In contrast, in order for prices to adjust smoothly, market participants would need common ways to assess both their own portfolio exposure to climate risk, as well as each other's market share. While better disclosure of climate-related financial information would not fully resolve the uncertainty stemming from these three sources of shocks, it would certainly make information less imperfect. Yet, the inability for market players to fully anticipate price adjustments implies that many actors could accumulate substantial unintentional exposures. 
Here, an important gap is represented by the lack of concise and comparable indicators of portfolio's exposure to transition risk that fails to provide investors with the right incentives to reallocate their portfolio.

A second limiting factor for market-based solutions to climate change arises from the fact that their functioning requires that market participants can assess their own market share and the one of their competitors, and that regulators can access such information. For instance, in the context of perfect competition, market-based solutions require that the market power of participants and in particular of incumbent players is known and negligible. This, in turn, implies that their market share should be not too large. The presence of market power could prevent markets to work as intended: for instance, in the energy market, it could adversely affect the operation of the electricity system by inducing distortions of energy price signals, resulting in inefficient investment decisions (Twomey et al. 2005). In addition, the presence of market power is relevant for policy makers and regulators because it could substantially undermine the intended benefits from changes in regulation. The optimal level of environmental regulations (such as the introduction of a carbon tax) to mitigate the cost of climate change has been widely debated in the context of perfect competition, with some scholars advocating more restrictive (Stern 2009) or more gradual interventions (Nordhaus 2007). Acemoglu et al. (2012) showed that market-based solutions to climate change could work also in the presence of energy sector monopoly and put the attention on the price effects on the direction of technical change. An implicit assumption of all these models is that market participants are able to assess their own market share as well as their competitors, since this is a crucial variable in determining decisions to enter or leave the market, as well as the portfolio's reallocation strategies. However, in the context of the transition to a low-carbon economy, it is not clear how to measure the market share of participants because financial actors invest at the same time in many economic sectors, which are potentially exposed to climate risk via the GHG emissions that they either produce directly or induce along the supply chain. As a result, the lack of common and concise measures of the relevant market share hampers both the ability of policy makers to introduce effective market regulations and competition policies, and the ability of mainstream investors to assess the possible effects of their own and their competitors' portfolio reallocation.

In order to fill in these two gaps, we propose two novel and complementary indices to characterize a financial actor's portfolio: (i) its "GHG exposure," capturing the exposure of the portfolio to climate transition risks, and (ii) its "GHG holding," capturing the market share of each financial actor weighted by its contribution to GHG emissions. By looking at these two dimensions simultaneously, we can identify those actors who are, at the same time, the most exposed to climate risks, and who are likely to have the largest influence both on price adjustments in the low-carbon transition and on the introduction of decarbonization policies.

We illustrate the policy insights that can be derived from the empirical application of these indices by combining GHG emissions data by country and economic sector (at the level of 1digit Nace Rev2 classification), with a dataset of portfolios of equity holdings and loans in the 17 countries that composed the Euro-Area in 2014, extracted from the Bureau Van Dijk (BvD) ORBIS database, and with loan data at the sector level obtained from the European Central Bank (ECB) data warehouse. The two indices help to inform the discussion on the introduction of a stable framework of incentives that would encourage the divestment from carbonintensive sectors and decrease the downside risk of low-carbon investment (also called derisking). Such an incentive framework would make the achievement of the COP21's target more likely and would reduce the risk for financial actors, governments, and citizens. 


\section{Data and methods}

\subsection{Data description}

\subsubsection{Financial data}

To run our analysis, we use the data provided by the Orbis/BvD database from which we selected 2804 listed companies and 11,488 shareholders with consolidated accounts for the 17 Euro-Area countries for year 2014 (Austria, Belgium, Cyprus, Estonia, Finland, France, Germany, Greece, Ireland, Italy, Luxembourg, Malta, the Netherlands, Portugal, Slovakia, Slovenia, and Spain), for a total of 27,955 equity holdings relationships. The Orbis/BvD database includes equity holdings of financial investors in listed companies recorded at the end of the accounting year, for the last year available. The Orbis/BvD classifies financial actors through the Shareholder Bureau Van Dijk (BvD Type) data field into standardized institutional categories. However, this classification does not perfectly match the traditional taxonomy of institutional investors. Banks and investment funds are often classified differently: e.g., Blackrock Inc. is considered a bank instead of an asset manager. In addition, in the case of asset managers (such as Blackrock Inc.), the data do not reliably distinguish between assets owned and assets under management (i.e., managed for other owners). In order to overcome these issues, we have reclassified financial actors according to the European Systems of Accounts (ESA 2010) classification of shareholders into standardized institutional categories. We obtained eight groups of financial actors: Banks, Other credit institutions (risk pooling and contractual savings institutions), Investment funds, Insurance and pension funds, Other financial services (e.g., foundations and research institutes), Industrial companies, Governments, and Individuals (e.g., private shareholders). The exposures of the groups of financial actors can be decomposed along the main types of financial instruments such as loans (e.g., non-tradable debt securities), bond holdings (e.g., tradable debt securities), and equity holdings (e.g., ownership shares including both those tradable on the stock market and those non-tradable).

In the Euro-Area, loans, equity share, and debt securities represent a total of $88 \%$ of financial assets in 2015. Loans account for 38\% (i.e., 53.2 trn EUR) of total assets, equity holdings (listed) for 33\% (i.e., 40.6 trn EUR), and bonds for 17\% (i.e., 21 trn EUR) (ECB data warehouse). Therefore, by focusing on loans and equity holdings, we cover more than two-thirds of the Euro-Area assets. Equity holdings in listed companies are the initial focus of our analysis because their information is the most accessible (including the identity of the owners, which is not the case for bonds). In addition, they are less likely to suffer from the bias of overrepresentation of big companies, which could affect the data on equity holdings in non-listed companies. From these data, we derive the relevant information on investors' exposure to listed companies by sector of economic activity and by year. Equity holdings represent $44 \%$ (4139.3 billion (bn) EUR) of investment fund's (IF's) total assets, which are equal to 9426.2 bn EUR, and 54\% (1177.7 bn EUR) of pension fund's (PF's) total assets, which are equal to 2160.7 bn EUR. Loans to nonfinancial corporations (NFC) represent a small but non-zero share of IF and PF's portfolios, respectively $6.2 \%$ (584.5 bn EUR) and $3 \%$ (64.6 bn EUR). In contrast, and not surprisingly, Banks (monetary financial institutions, MFIs), which have the highest value of total assets with 31,195.4 bn EUR in the Euro-Area in 2014, have the largest exposure in loans to NFC that represent $13.8 \%$ (4315.9 bn EUR) of banks' total assets $(31,195.4$ bn EUR, see Table A1). 
In addition, we consider data on Euro-Area banks' loans to listed companies made available by the ECB data warehouse, which provides harmonized balance sheets of all MFIs that are resident in the Euro-Area, including inter-MFI positions on a gross basis, according to the Regulation ECB/2008/32. According to the ECB data warehouse definition, MFIs include the Euro-Area-resident credit institutions (as defined in the European Union (EU) law) and all other resident financial institutions whose business is to receive deposits and/or close substitutes for deposits from entities other than MFIs and, for their own account (at least in economic terms), to grant credit and/or invest in securities. Banks' loans breakdown by NACE Rev2 sectors of economic activity is less granular than in the case of equity holdings: aggregation occurs for sectors D and $\mathrm{E}, \mathrm{H}$ and $\mathrm{J}$, and $\mathrm{L}, \mathrm{M}$, and $\mathrm{N}$.

\subsubsection{GHG emissions data and sectors of economic activity}

Because our analysis focuses on the Euro-Area, we use the annual GHG inventory report compiled by the European Environment Agency (EEA) on behalf of the EU and made available on the Eurostat database. Estimates of GHG emissions are produced for NACE Rev2 sectors of economic activity according to the technological source of emissions, following the IPCC's recommendations.

We include $\mathrm{CO}_{2}$ emissions, Methane emissions in $\mathrm{CO}_{2}$ equivalents, and Nitrous oxide emissions in $\mathrm{CO}_{2}$ equivalents for each NACE Rev2 sector of economic activity per each country of the EU, in thousand tonnes. We then aggregate the values for the 17 countries which belonged to the Euro-Area in 2014. We consider only Scope 1 (direct) GHG emissions because data are mostly available, in comparison to Scope 2 (indirect emissions) and Scope 3 (induced emissions). We follow the classification of economic sectors called NACE Rev2 (Nomenclature statistique des activités économiques dans la Communauté européenne), which is adopted by Eurostat to classify the economic activities in the EU at a 4-digit level. Sectors are listed from A-Agriculture, forestry, and fishing to U-Activities of extraterritorial organizations and bodies. We consider sectors of economic activity from A-Agriculture, forestry, and fishing to $\mathrm{L}$-Real estate activities because they represent the most of GHG emissions in $\mathrm{CO}_{2}$ equivalent on the total (96.29\%) in 2014 (see Table 2 Sector DElectricity, gas, steam, and air conditioning supply is responsible for the most of the emissions in 2014 (694,986.503 thousand tonnes) followed by sector C-Manufacturing $(602,048.885$ thousand tonnes) and by sector A-Agriculture $(352,471.288$ thousand tonnes).

\subsection{Definition of the indices}

We develop two complementary indices that allow us to analyze two main dimensions of investors' exposure to climate risk, providing a systemic overview of the relation between financial exposure and GHG emissions across financial actors. For each NACE Rev2 economic sector $j$, we compute its share $S_{j}$ of GHG emissions out of the total GHG emissions from all economic activities in the Euro-Area in 2014. Let us now consider the equity holdings portfolios. For a given financial actor $i$ owning equity holdings in the sector $j$ for an monetary value $A_{i j}$, we compute its relative exposure to each economic sector $j, W_{i j}=A_{i j} / \sum_{l} A_{i l}$, where the index $l$ runs over the set of all the sectors. Notice that by construction, it holds $\Sigma W_{i j}=1$. The "GHG 
exposure" index $\left(\mathrm{EE}_{i}\right)$ is defined as the sum of the relative exposures of the actor $i$ across economic sectors weighted by the relative share of emissions of each sector:

$$
\mathrm{EE}_{i}=\sum_{j} S_{j} W_{i j}
$$

For instance, an investor with a portfolio entirely concentrated on sector D-Electricity, etc. has a value of the index $\mathrm{EE}_{i}$ higher than an investor with a portfolio concentrated on $\mathrm{K}$ Financial, etc. because the share of emissions of sector D is higher than that of sector K. The "GHG exposure" index captures the GHG emissions intensity of the portfolio of each financial actor according to the sectors to which it is most exposed and according to the emission shares of those sectors. The extension of this formula to the case of banks' loans is straightforward. We also compute the market share of each actor $i$ in each sector $j$ as $M_{i j}=A_{i j} / \sum_{k} A_{k j}$, where the index $k$ runs over the set of all the actors. The "GHG holding" index is defined as the sum of the market shares of the actor $i$ across economic sectors, weighted by the relative share of emissions of each sector:

$$
\mathrm{EH}_{i}=\sum_{j} S_{j} M_{i j}
$$

The "GHG holding" index $\mathrm{EH}_{i}$ captures the share of the GHG emissions "held" by each financial actor across all economic sectors and in comparison with the totality of actors $k$.

Our approach allows us to explore two complementary and fundamental dimensions of investors' portfolios in relation to climate risk. The first dimension addresses the question of how much is each financial actor exposed to climate risk through its portfolio, given the GHG emissions represented by its assets. It captures the share (and value) of financial actors' portfolios that is at risk of stranding in the case of abrupt adjustment of asset prices. The second dimension addresses the question of what are the GHG emissions that each financial actor "holds" through its portfolio in relation to the other actors. It captures the relative importance of financial actors in decarbonization paths, showing who are the key financial actors in terms of both their market share and the value of the GHG emissions they could "move" in response to the introduction of either decarbonization policies or green incentives.

\section{Results}

\subsection{Empirical results}

The value of the total market capitalization of equity holdings of listed companies in the 17 countries of the Euro-Area in 2014 is 2,936,351,029,3 thousand USD, with highest values owned by Industrial companies (1,020,185,951,000 USD), Investment funds (801,178,754,200 USD), and Banks (347,640,118,000 USD).

The highest equity portfolios' exposure to NACE Rev2 sectors for all actors' portfolios in the Euro-Area in 2014 is on sector C Manufacturing, with peaks for Individuals $(75.56 \%$ of their equity portfolio) and Industrial companies (55.53\%). Insurance and pension funds, as well as Banks, are mostly exposed to sector K Financial and insurance activities, respectively for 56.95 and $36.82 \%$ of their equity portfolio. The lowest exposure of all financial actors' equity portfolios is on sector A Agriculture, forestry, and fishing, as a result of companies' low market capitalization. The value of each financial actor equity holdings' portfolio by sector of activity is reported in Table A2. 
Table 1 shows the market share of each financial actor's type in each sector of economic activity, as well as the total market share of each financial actor's equity portfolio. Industrial companies and Investment funds have the highest total market share, respectively 35 and $27 \%$ of the total. The highest market share, normalized by total exposure of all financial actors, belongs to Industrial companies in sectors I Accommodation and food service activities (59\%) and $\mathrm{E}$ Water supply, sewerage, waste management, and remediation activities (46\%).

Table 2 shows the breakdown of GHG emissions by NACE Rev2 sector of economic activity for the 17 Euro-Area countries considered. The most GHG-intense sectors according to the Eurostat Scope 1 classification are sector D Electricity, gas, steam, and air conditioning supply ( $30.65 \%$ of total $\mathrm{GHG}$ emissions in $\mathrm{CO}_{2}$ equivalent), followed by sector $\mathrm{C}$ Manufacturing $(26.55 \%)$ and sector A Agriculture, forestry, and fishing (15.55\%).

Table 3 shows the equity portfolios' exposure to NACE Rev2 sectors for each financial actor in the Euro-Area in 2014. The most exposed actors to sector D, which records the highest GHG emissions' intensity (see Table 2), are governments (39.5\% of their equity), mostly through their ownership or participation in utility and extraction companies. In contrast, individual families and industrial companies record the highest equity portfolio's exposure to sector C (respectively $75.6 \%$ and $55.4 \%$ ). The lowest equity portfolios' exposure is on sector A-Agriculture, for all financial actors.

The information provided in Tables 1, 2, and 3 is used to compute the two indices, whose results are then displayed in Table 4, which reports the results of the GHG emissions exposure index calculated for each financial actor, and the GHG emissions holding index. Governments, individuals, and investment funds' portfolios display the highest GHG emissions exposure ("GHG exposure index"), while Industrial companies and Investment funds have the highest market share of GHG emissions ("GHG holding index").

Figure 1 plots the GHG holding index versus the GHG exposure index. GHG exposure and GHG holding are two complementary and yet fundamental dimensions of climate transition risk. Indeed, actors in the top-right quadrant are those who are at the same time most exposed to GHG emissions and most likely to have a large impact on the market if they were to reallocate their portfolios in order to avoid stranded assets. In the data considered in our first exercise, i.e., equity holdings of the Euro-Area, both indices display heterogeneity across financial actors' types. Governments have the highest GHG exposure $(0.211)$ but play a minor role on financial markets in terms of total market share. Indeed, the size of Governments' bubble is much smaller than that of Industrial companies. The latter emerges as a key stakeholder, as a result of its high GHG exposure combined with its even higher GHG holding due to its total market share. Governments' position on the graph reflects the concentration of exposure in sectors with high GHG emissions share (such as sector C Manufacturing and D Electricity, etc.). Similar to Governments, Individuals display high values for the GHG exposure index (0.200) but have relatively low values for the GHG holding, as a consequence of their lower market share. Their GHG exposure index is also driven by their high portfolio's exposure to sector $\mathrm{C}$ and sector $\mathrm{D}$. Investment funds are the other key financial actor (displayed by the second-sized bubble), and their result is driven by the value of the GHG holding index (0.225) and their total market share. For both Industrial companies and Investment funds, their high market share i.e., the financial weight on the equity market contributes to the final result.

The information provided by the two indices captures the complexity of climate policies. For instance, Industrial companies and Investment funds are very different according to their business type and thus would require different policy incentives for divestment from carbon 


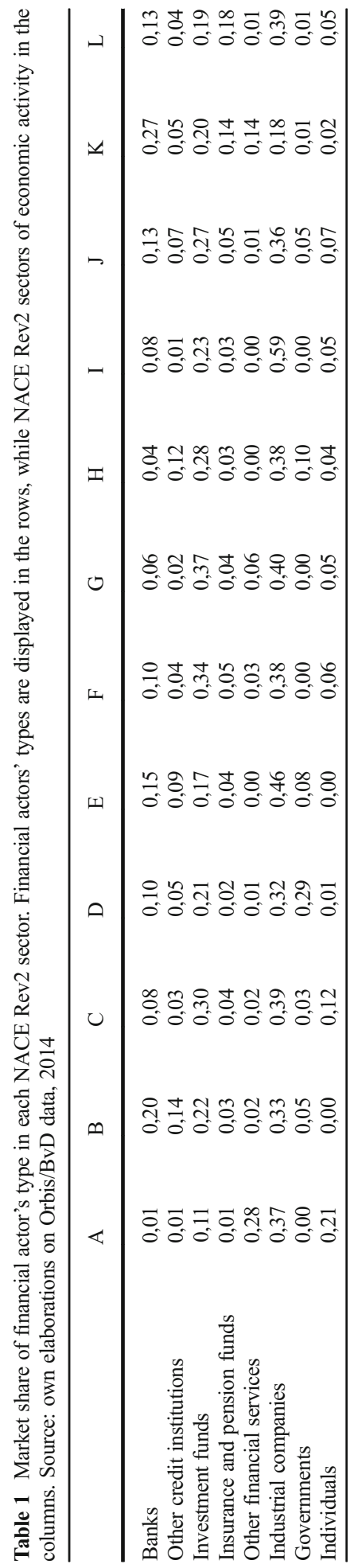


Table 2 Share of GHG emissions (in $\mathrm{CO}_{2}$ equivalents) by NACE Rev2 sector in the Euro-Area, 2014. Source: Eurostat. The NACE Rev2 sectors not included in the table represent only roughly $3.7 \%$ of GHG emissions and include professional activities, teaching, and services. We excluded them from our analysis

\begin{tabular}{ll}
\hline Sector NACE Rev2 1-digit level & GHG emissions share (\%) \\
\hline A-Agriculture, forestry and fishing & 15.55 \\
B-Mining and quarrying & 0.96 \\
C-Manufacturing & 26.55 \\
D-Electricity, gas, steam, and air conditioning supply & 30.65 \\
E-Water supply, sewerage, waste management, and remediation activities & 5.24 \\
F-Construction & 1.45 \\
G-Wholesale and retail trade, and repair of motor vehicles and motorcycles & 2.03 \\
H-Transportation and storage & 12.73 \\
I-Accommodation and food service activities & 0.53 \\
J-Information and communication & 0.28 \\
K-Financial and insurance activities & 0.20 \\
L-Real estate activities & 0.12 \\
Total & 96.29 \\
\hline
\end{tabular}

assets. It would be easier and faster for Investment funds to reallocate their equity holdings than it would be for Industrial companies. Indeed, for Industrial companies, equity holdings typically represent shares of ownership in subsidiaries operating also in their core business sector.

Table A5 in the Appendix reports the values of the GHG exposure index for commercial banks based on their loans to non-financial corporations (NFC) in 2014. The contributions to the index values are computed for each sector of economic activity. The highest contribution comes from sector $\mathrm{C}$ and the lowest from sector $\mathrm{B}$. The latter result can be explained by the low level of reliance of mining and fossil fuel extraction companies on credit loans in the EuroArea in 2014. The GHG exposure index calculated on banks' loan portfolio is lower than the same value calculated on banks' equity portfolio, respectively 0.074 and 0.091 . The difference comes from the different allocation of banks' loans and equity holdings across sectors (for instance, banks lend more to real estate than they hold in real estate's equity).

\subsection{Discussion around data availability and implications for results}

The methodology proposed in this article has a general validity and can be applied to a generic dataset of portfolios for which the economic sectors of the investments are known. However,

Table 3 Financial actors' equity exposure in each NACE Rev2 sector of economic activity, as a percentage of each financial actor's total equity portfolio. The financial actors' types are reported in the rows, while the NACE Rev2 sectors of economic activity are reported in the columns. Source: own elaborations on Orbis/BvD data, 2014

\begin{tabular}{llllllllllllll}
\hline Financial actor/NACE Rev2 sector & $\mathrm{A}$ & $\mathrm{B}$ & $\mathrm{C}$ & $\mathrm{D}$ & $\mathrm{E}$ & $\mathrm{F}$ & $\mathrm{G}$ & $\mathrm{H}$ & $\mathrm{I}$ & $\mathrm{J}$ & $\mathrm{K}$ & $\mathrm{L}$ & Total \\
\hline Banks & 0 & 5.69 & 31.8 & 4.86 & 0.7 & 2.6 & 1.7 & 1.53 & 0.6 & 11.2 & 36.8 & 2.5 & 100 \\
Other credit institutions & 0.1 & 10.7 & 30.2 & 6.37 & 1.2 & 2.7 & 1.8 & 11.2 & 0.2 & 15.2 & 18.3 & 2.1 & 100 \\
Investment funds & 0.1 & 2.8 & 55.4 & 4.68 & 0.4 & 3.7 & 4.7 & 4.52 & 0.7 & 10 & 11.4 & 1.6 & 100 \\
Insurance and pension funds & 0.1 & 2.03 & 34.4 & 2.37 & 0.4 & 2.8 & 2.2 & 2.17 & 0.5 & 8.13 & 37.9 & 7.1 & 100 \\
Other financial services & 2 & 1.59 & 28.1 & 0.84 & 0 & 2.1 & 5.1 & 0.49 & 0 & 2.19 & 57 & 0.6 & 100 \\
Industrial companies & 0.3 & 3.27 & 55.5 & 5.51 & 0.8 & 3.3 & 4 & 4.74 & 1.4 & 10.5 & 8.13 & 2.6 & 100 \\
Governments & 0 & 4.03 & 29 & 39.5 & 1.1 & 0.2 & 0.2 & 9.75 & 0.1 & 11.7 & 4.15 & 0.3 & 100 \\
Individuals & 0.8 & 0.21 & 75.6 & 0.96 & 0 & 2.2 & 2.2 & 2.56 & 0.6 & 9.9 & 3.34 & 1.7 & 100 \\
\hline
\end{tabular}


Table 4 The GHG exposure index and the GHG holding index. The table reports the values of the GHG emissions exposure index and the GHG emissions holding index calculated for each financial actor across sectors (for a breakdown of the indices by sector, see Tables A3 and A4 in Appendix)

\begin{tabular}{lll}
\hline Financial actor/indices & GHG exposure index $(\mathrm{EE})$ & GHG holding index $(\mathrm{EH})$ \\
\hline Banks & 0.101 & 0.070 \\
Other credit institutions & 0.116 & 0.046 \\
Investment funds & 0.166 & 0.225 \\
Insurance and pension funds & 0.095 & 0.027 \\
Other financial services & 0.083 & 0.054 \\
Industrial companies & 0.168 & 0.352 \\
Governments & 0.211 & 0.114 \\
Individuals & 0.200 & 0.075 \\
\hline
\end{tabular}

data availability represented a main issue for our analysis. In particular, the accuracy of the results would certainly benefit from a more granular and standardized disclosure of financial information on investors' portfolios. To this end, and in line with the recommendations of the European Commission's High Level Experts Group on Sustainable Finance (HLEG 2017), public funding could be devoted to the creation of an open database containing granular data on exposures of financial actors to sectors of economic activity and emissions. Such investment would allow researchers to carry out more-detailed analyses and to replicate more easily the previous results, supporting the development of better metrics and methods for climaterelated financial disclosure advocated by the G20's FSB TCFD (2017).

As regards financial data from the BvD ORBIS database, we encountered the following issues. Entities classified as persons or families (which account for circa $30 \%$ of shareholders) do not have a NACE code and have been classified as Individuals. Then, different equity holdings may be recorded as owned by economic entities, corresponding to different business arms (e.g., the Goldman Sachs group comprises a banking arm as well as investment funds) belonging to the same business group. We have kept the ownership at the level of consolidation that was provided in the data because our aim in this analysis is to aggregate the holdings in terms of institutional sectors. We are not interested here in aggregating them by business

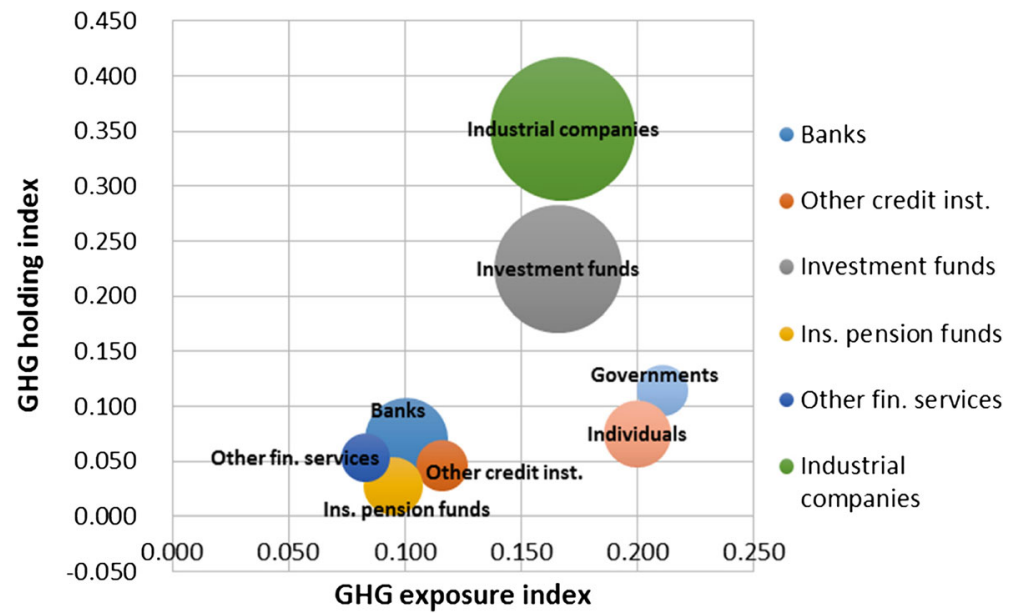

Fig. 1 Bubble chart of the two indices for several aggregated financial actors. $X$-axis: GHG exposure index. $Y$ axis: GHG holding index. The size of the bubble is proportional to the market share of each financial actor type 
groups. However, the way in which BvD ORBIS classifies shareholders from the financial sectors into banks, investment funds, and hedge funds is sometimes unsuited for our analysis (e.g., some asset managers are classified as banks). Therefore, whenever the NACE code of the shareholder was available, we have reclassified them into institutional sectors (e.g., banks, investment funds) following as closely as possible the ESA 2010 standards. The detailed correspondence is reported in Table A8 of the Appendix.

We have focused here on data of the Euro-Area because value and allocation of shares for investors from several countries, in particular from China and Russia, suffers from underreporting issues.

Debt securities are important when we look at governments, pension funds, and banks' direct exposure. Banks alone in the Euro-Area hold government bonds for 1.7 trn EUR and corporate bonds for EUR 1.3 trn (ECB data warehouse). However, the information on the economic sector of the issuer of debt securities owned by financial actors are not provided. This is an important limitation for the analysis of exposures because the expansionary monetary policy, enforced by the ECB through its Long Term Refinancing Operation first, and the Quantitative Easing (QE) policy since June 2016 target specifically the purchase of corporate debt securities. It would be desirable that this information could be made available in the next future.

Data on GHG emissions by sector of companies' economic activities at the NACE 2-digit code aggregation are provided by Eurostat only until 2014. In our analysis, we have used the information on the contribution of each economic sector to the total GHG emissions at the Euro-Area level. In principle, one could use the contribution of each sector at the country level. However, Scope 1 and Scope 2 data underestimate the role that the sector B-Mining and quarrying-plays on global emissions. Indeed, sector $\mathrm{B}$ is indirectly responsible for $\mathrm{CO}_{2}$ emissions in the atmosphere through the use of fossil fuels an input for production by the other sectors of economic activity, in particular transport, utility, housing, and energy-intensive sectors such as manufacturing. Improving GHG emissions tracking and reporting from fossil fuel extraction sectors is fundamental to assess the sector's exposure to carbon stranded assets, and the carbon intensity of investors' portfolios (see for instance the 2 Degrees Investing Initiative's (2015) campaign on investors' climate disclosure, the Global Reporting Initiative (GRI) Guidelines and the Carbon Disclosure Project (CDP) 2011). Finally, the level of aggregation of the NACE Rev2 classification of economic activities for which GHG emissions are available hides the heterogeneity of the contribution of different activities classified within the same sector to GHG emissions. For instance, sector C-Manufacturing, which contributes to $26 \%$ circa of cumulative $\mathrm{CO}_{2}$ emissions, includes a very broad range of activities such as Manufacture of food products, beverages, and tobacco products (CA), Manufacture of coke and refined petroleum products $(\mathrm{CD})$, and Manufacture of computer, electronic, and optical products $(\mathrm{CI})$, which at the current stage, cannot be disentangled.

\section{Conclusion}

The G20's FSB TCFD has identified a key information gap for the introduction of effective market-based solutions to climate change, i.e., the need for better disclosure on business and financial actors' exposure to climate risk. However, even in the presence of more granular and systematic information, the lack of concise and comparable indicators to measure the main economic variables required by market participants to make their decisions, constitutes an 
additional informational gap that need to be addressed. As the two most critical dimensions for market participants, we have focused on the problem of measuring their vulnerability, in terms of exposures of their portfolios to climate transition risk, and their relevance, in terms of their effective market share, in the context of the low-carbon transition. To this end, we have introduced a GHG exposure index that weighs the exposure of the portfolio to the various sectors by the contribution of the sector to the GHG emissions. We have also introduced a GHG holding index that weighs the market share of the portfolio in each sector by the contribution of the sector to the GHG emissions.

We are well aware of the issues in the estimations of the GHG emissions of each sector of activity, including the fact that emissions induced by a sector such as B in the supply chain is currently not taken into account. We are also aware of the issues in the classification of complex economic activities into a specific sector in order to assign them a level of contribution to GHG emissions. Yet, these two indices have the advantage that they can be easily computed in a standardized fashion by all market participants and regulators. Therefore, they have the potential to set an initial and commonly agreed benchmark for the evaluation of portfolios and market strategy decisions. This benchmark can then be refined, when new, and more granular information becomes available.

In this paper, we have illustrated the use of the two indices on a data set covering equity holdings and bank loans in the Euro-Area in 2014. Industrial companies and Investment funds emerge as key stakeholders in our dataset because they are at the same time vulnerable and yet relevant. Indeed, they have high levels of GHG exposure but also high levels of GHG holding because, as institutional sectors, they have the largest market share in several carbon-intense sectors. Investment funds, however, typically manage funds on behalf of clients, and in particular, to a large extent, of pension funds. Thus, the potential loss deriving from stranded assets in GHG-intensive sectors could end up affecting households through pension funds and pension schemes. This is a relevant insight in the discussion on market-based solution to climate change. We also found that Governments have the highest level of GHG exposure, through their portfolio of equity holdings on sector D-Electricity, etc. This result highlights the contradiction between governments' commitments to the COP21's target and their current exposure to carbon-intense assets. It follows that governments could play a key role in promoting the transition to a low-carbon economy by greening their own portfolios. When looking at the contributions to the GHG exposure index, we see that all financial actors are exposed to sector C-Manufacturing, and sector D-Electricity, etc., which are the most relevant sectors in terms of GHG emissions. Therefore, the introduction of incentives targeting these sectors could contribute to mobilize capital into low-carbon investments, creating opportunities for profits from divesting from carbon-intense assets. This would help mitigating the negative effects of climate transition risks on the potential "losers," making low-carbon transition solutions acceptable for them.

Acknowledgements Open access funding provided by Vienna University of Economics and Business (WU). We acknowledge the useful comments of two anonymous reviewers. We are grateful to Amal-Lee Amin and Gianleo Frisari from the Inter-American Development Bank and to Mauro Napoletano for fruitful comments on earlier versions of the manuscript. S.B. acknowledges financial support from the Swiss National Fund Professorship grant no. PP00P1-144689 and from the European Commission through the Future and Emerging Technologies (FET) projects SIMPOL (grant no. 610704) and DOLFINS (grant no. 640772), and the project SEI Metrics (grant no. 649982).

Open Access This article is distributed under the terms of the Creative Commons Attribution 4.0 International License (http:/creativecommons.org/licenses/by/4.0/), which permits unrestricted use, distribution, and reproduction in any medium, provided you give appropriate credit to the original author(s) and the source, provide a link to the Creative Commons license, and indicate if changes were made. 


\section{References}

2 Degrees Investing Initiative, UNEP-FI initiative, World Resource Institute (2015) Climate strategies and metrics: Exploring options for institutional investors. http://www.unepfi.org/fileadmin/documents/climate strategies metrics.pdf

Acemoglu BD, Aghion P, Bursztyn L, Hemous D (2012) The environment and directed technical change. Am Econ Rev 102(1):131-166. https://doi.org/10.1257/aer.102.1.131

Anthony KW, Daanen R, Anthony P, Deimling TS Von, Ping C, Chanton JP, Grosse G (2016) Methane emissions proportional to permafrost carbon thawed in Arctic lakes since the 1950s. Nat Geosci doi: https://doi.org/10.1038/NGEO2795

Batten S, Sowerbutts R, Tanaka M (2016) Let's talk about the weather: the impact of climate change on Central Banks. Bank of England Staff Working Paper No. 603

Battiston S, Mandel A, Monasterolo I, Schuetze F, Visentin G (2017) A climate stress-test of the EU financial system. Nat Clim Chang 7, 283-288. https://doi.org/10.1038/nclimate3255

Caldecott B, McDaniels J (2014) Stranded generation assets: implications for European capacity mechanisms, energy markets and climate policy. Stranded Assets Programme, SSEE, University of Oxford, p 1-62

Carney M, Bloomberg M (2016) How to make a profit from defeating climate change. Climate Change Opinion, The Guardian

Dietz S, Bowen A, Dixon C, Gradwell P (2016) Climate value at risk of global financial assets. Nat Clim Chang 6, 676-689. https://doi.org/10.1038/nclimate2972

ESRB Advisory Scientific Committee (2016) Too late, too sudden: transition to a low-carbon economy and systemic risk. Tech Rep

European System of National and Regional Accounts (Eurostat, 2010) http://ec.europa.eu/eurostat/web/esa-2010

Financial Stability Board Task Force on Climate-Related Financial Disclosures (TFCD) (2017) Final report: recommendations of the Task Force on Climate-related Financial Disclosures, June 2017. Available at: https://www.fsb-tcfd.org/wp-content/uploads/2017/06/FINAL-TCFD-Report-062817.pdf

Foxon TJ (2006) Technology lock in and the role of innovation. In: Atkinson G, Dietz S, Neumayer E (eds) Handbook of sustainable development. Edward Elgar, Cheltenham, UK

Greenwald BC, Stiglitz JE (1986) Externalities in economies with imperfect information and incomplete markets. Q J Econ 101(2), 229-264

GRI and CDP (2011) Linking GRI and CDP: how do the Global Reporting Initiative Reporting Guidelines match with the Carbon Disclosure Project questions? https://www.globalreporting.org/resourcelibrary/LinkingGRI-And-CDP.pdf

High Level Experts Group on Sustainable Finance (HLEG) (2017) Financing a sustainable European economy. Interim Report. https://ec.europa.eu/info/sites/info/files/170713-sustainable-finance-report_en.pdf

IPCC (2014) Climate change 2014: synthesis report. Contribution of Working Groups I, II and III to the Fifth Assessment Report of the Intergovernmental Panel on Climate Change, Core Writing Team, R.K. Pachauri and L.A. Meyer. doi:https://doi.org/10.1017/CBO9781107415324.004

Leaton (2012) Unburnable carbon. Are the world financial markets carrying a carbon bubble? http://www. carbontracker.org/report/carbon-bubble. Accessed 3 May 2016

Mas-Colell A, Whinston MD, Green JR (1995) Microeconomic theory. Oxford university press, New York

Nordhaus WD (2007) A review of the stern review on the economics of climate change. J Econ Lit 45(3), 686702

Rogelj J, Elzen M Den, Höhne N, Fransen T, Fekete H, Winkler H, Schaeffer R, Sha F (2016) Paris agreement climate proposals need a boost to keep warming well below $2^{\circ} \mathrm{C}$. Nature 534, 631-639. https://doi. org/10.1038/nature 18307

Stern N (2009) A blueprint for a safer planet: how to manage climate change and create a new era of progress and prosperity. Bodley Head, London

Twomey P, Green R, Neuhoff K, Newbery D (2005) A review of the monitoring of market power: the possible roles of transmission system operators in monitoring for market power issues in congested transmission systems. J Energ Lit 11(2), 3-54

Unruh GC (2000) Understanding carbon lock-in. Energy Pol 28(12), 817-830 